Article

\title{
Influential Mechanism of Natural Organic Matters with Calcium Ion on the Anion Exchange Membrane Fouling Behavior via xDLVO Theory
}

\author{
Zhun Ma ${ }^{1}$, Lu Zhang ${ }^{1}$, Ying Liu ${ }^{1}$, Xiaosheng Ji ${ }^{2, *}$, Yuting Xu ${ }^{1}$, Qun Wang ${ }^{1, *}$, Yongchao Sun ${ }^{1,3}$, \\ Xiaomeng Wang ${ }^{1}$, Jian Wang ${ }^{4}$, Jianliang Xue ${ }^{5}$ and Xueli Gao ${ }^{3}$ \\ 1 College of Chemical and Biological Engineering, Shandong University of Science and Technology, \\ Qingdao 266590, China; skdmaz919@sdust.edu.cn (Z.M.); luluzh5709@163.com (L.Z.); \\ ly19980407@163.com (Y.L.); xyt15153393708@163.com (Y.X.); yongchao_sun@163.com (Y.S.); \\ 15764237673@163.com (X.W.) \\ 2 Sanya Institute of Oceanology, Chinese Academy of Sciences, Sanya 572000, China \\ 3 Key Laboratory of Marine Chemistry Theory and Technology, Ministry of Education, College of Chemistry \\ and Chemical Engineering, Ocean University of China, Qingdao 266100, China; gxl_ouc@126.com \\ 4 The Institute of Seawater Desalination and Multipurpose Utilization, Ministry of Natural Resources (MNR), \\ Tianjin 300192, China; swordking8856@163.com \\ 5 College of Safety and Environmental Engineering, Shandong University of Science and Technology, \\ Qingdao 266590, China; 11-1382@163.com \\ * Correspondence: jixiaoshen@zju.edu.cn (X.J.); wangqun87@sdust.edu.cn (Q.W.)
}

check for updates

Citation: Ma, Z.; Zhang, L.; Liu, Y.; Ji, X.; Xu, Y.; Wang, Q.; Sun, Y.; Wang, X.; Wang, J.; Xue, J.; et al. Influential Mechanism of Natural Organic Matters with Calcium Ion on the Anion Exchange Membrane Fouling Behavior via xDLVO Theory. Membranes 2021, 11, 968. https:// doi.org/10.3390/membranes11120968

Academic Editor: Yi-Li Lin

Received: 5 November 2021

Accepted: 6 December 2021

Published: 9 December 2021

Publisher's Note: MDPI stays neutral with regard to jurisdictional claims in published maps and institutional affiliations.

Copyright: (c) 2021 by the authors. Licensee MDPI, Basel, Switzerland. This article is an open access article distributed under the terms and conditions of the Creative Commons Attribution (CC BY) license (https:/ / creativecommons.org/licenses/by/ $4.0 /)$.

\begin{abstract}
The fouling mechanism of the anion exchange membrane (AEM) induced by natural organic matter (NOM) in the absence and presence of calcium ions was systematically investigated via the extended Derjaguin-Landau-Verwey-Overbeek (xDLVO) approach. Sodium alginate (SA), humic acid (HA), and bovine serum albumin (BSA) were utilized as model NOM fractions. The results indicated that the presence of calcium ions tremendously aggravated the NOM fouling on the anion exchange membrane because of Ca-NOM complex formation. Furthermore, analysis of the interaction energy between the membrane surface and foulants via xDLVO revealed that short-range acid-base $(\mathrm{AB})$ interaction energy played a significant role in the compositions of interaction energy during the electrodialysis (ED) process. The influence of NOM fractions in the presence of calcium ions on membrane fouling followed the order: SA $>$ BSA $>$ HA. This study demonstrated that the interaction energy was a dominating indicator for evaluating the tendency of anion exchange membranes fouling by natural organic matter.
\end{abstract}

Keywords: membrane fouling; xDLVO theory; natural organic matters; anion exchange membrane

\section{Introduction}

Electrodialysis (ED) has been not only extensively employed for the desalination of seawater and brackish water but also actively utilized for the reclamation of highsalinity industrial wastewater [1-8]. However, a serious impediment in operation of the ED process is ion-exchange membranes (IEMs) fouling, which would increase the electric resistance of the membrane and decrease current efficiency, resulting in deterioration of the electrodialysis performance [9-13]. Many studies have indicated that the natural organic matter (NOM) played a crucial role in ion exchange membranes fouling, especially the anion exchange membranes (AEMs) fouling [14-16]. In general, the AEMs fouling was attributed to the electrostatic interaction between the NOM and fixed positive charged functional groups of AEMs [17-19]. In addition, the AEMs were susceptible to be fouled due to hydrophilic/hydrophobic interaction and geometrical factors containing the chemical structure of foulants and surface morphology of AEMs [20,21]. Furthermore, several studies have found that inorganic ions can change organic material characteristics, affecting the 
attachment of NOM to the membrane surface [22-24]. As a common inorganic ion, calcium ions easily react with the surface of organic molecules and form calcium-carboxylate complex formation, which would aggravate membrane organic fouling [25,26].

Membrane fouling, essentially attributed to interface interactions between the membrane surface and foulants in aqueous solution, is a big obstacle to the ED process for wastewater treatment [27]. Therefore, analysis of these interface interactions may give new insight to understanding the mechanism of membrane fouling. The xDLVO theory is usually used to interpret these interactions and then to investigate the membrane fouling mechanism $[28,29]$. Moreover, this theory is a method for quantitatively studying the interfacial interaction between the membrane surface and foulants (Lishitz-van der waals (LW), electrostatic (EL), and short-path acid-base (AB) interaction energy), which can effectively predict the trend of membrane fouling. Lin et al. indicated that the xDLVO theory could verify the impacts of different components of organic matter on ultrafiltration membrane fouling [30]. Furthermore, Lin et al. employed the xDLVO theory to predict the organic membranes fouling in ultrafiltration systems, and the simulation results were in agreement with the experimental results [31]. Kim et al. used interfacial forces based on xDLVO to elucidate membrane fouling in the RO process [32]. Shan et al. used HA as a model foulant to study its fouling behavior on super-wetting nanofiltration membranes applying xDLVO approach. They testified that the super-hydrophilic membrane had the strongest repulsion force to HA due to the highest positive total interaction energy value [27]. Zhao et al. utilized xDLVO theory to quantitatively validate the interfacial interactions in the nanofiltration membrane fouling process under various organic matter and $\mathrm{Ca}^{2+}$ concentration [33]. However, to the best of our knowledge, there are no reports on the application of $\mathrm{xDLVO}$ theory to predict and evaluate anion exchange membrane fouling in the ED process. Consequently, it is very important to investigate the membrane-foulants interaction energy to give an insight into the fouling mechanism and to develop effective prevention strategies of membrane fouling in the application of ED.

The motivation of the study was to explore the fouling mechanism of natural organic matters combined with or without calcium ions on AEMs. The interaction energy was calculated by $x D L V O$ theory to elucidate how the behavior of calcium ions aggravated the organic AEMs fouling during the ED process. The membrane surface properties were investigated by contact angle, transform infrared spectroscopy (FTIR), and scanning electron microscope (SEM) in order to verify the feasibility of xDLVO theory in predicting AEMs fouling during the ED process. Experimental results were expected to comprehend the AEMs fouling mechanisms of natural organic matter combined with calcium ions during the ED process via $x D L V O$ theory.

\section{Theory}

The interaction energy calculated by $x D L V O$, membrane-foulants interaction energy in aqueous media, is the summation of LW, $\mathrm{AB}$, and EL interactions, as follows [29]:

$$
\mathrm{U}_{\mathrm{mlf}}^{\mathrm{XDLVO}}=\mathrm{U}_{\mathrm{mlf}}^{\mathrm{EL}}+\mathrm{U}_{\mathrm{mlf}}^{\mathrm{LW}}+\mathrm{U}_{\mathrm{mlf}}^{\mathrm{AB}}
$$

where $\mathrm{U}_{\mathrm{mlf}}^{\mathrm{XDVO}}\left(\mathrm{mJ} / \mathrm{m}^{2}\right)$ is the total interaction energy between the foulants and membrane surface, $\mathrm{U}_{\mathrm{mlf}}^{\mathrm{EL}}\left(\mathrm{mJ} / \mathrm{m}^{2}\right)$ is the EL interaction energy, $\mathrm{U}_{\mathrm{mlf}}^{\mathrm{LW}}\left(\mathrm{mJ} / \mathrm{m}^{2}\right)$ is the $\mathrm{LW}$ interaction energy, and $U_{\mathrm{mlf}}^{A B}\left(\mathrm{~mJ} / \mathrm{m}^{2}\right)$ is the $A B$ interaction energy. In addition, " $\mathrm{m}$ ", " 1 ", and " $\mathrm{f}$ " denote the membrane, water, and foulants, respectively.

Correspondingly, $\mathrm{U}_{\mathrm{mlf}}^{\mathrm{LW}}, \mathrm{U}_{\mathrm{mlf}}^{\mathrm{AB}}$, and $\mathrm{U}_{\mathrm{mlf}}^{\mathrm{EL}}$ can be expressed as,

$$
\begin{gathered}
\mathrm{U}_{\mathrm{mlf}}^{\mathrm{LW}}(\mathrm{y})=2 \pi \Delta \mathrm{G}_{\mathrm{y}_{0}}^{\mathrm{LW}} \frac{\mathrm{y}_{0}^{2} \mathrm{a}_{\mathrm{c}}}{\mathrm{y}} \\
\mathrm{U}_{\mathrm{mlf}}^{\mathrm{AB}}(\mathrm{y})=2 \pi \mathrm{a}_{\mathrm{c}} \lambda \Delta \mathrm{G}_{\mathrm{y}_{0}}^{\mathrm{AB}} \exp \left[\frac{\mathrm{y}_{0}-\mathrm{y}}{\lambda}\right]
\end{gathered}
$$




$$
\mathrm{U}_{\mathrm{mlf}}^{\mathrm{EL}}(\mathrm{y})=\pi \varepsilon_{0} \varepsilon_{\mathrm{r}} \mathrm{a}_{\mathrm{c}}\left[2 \zeta_{\mathrm{f}} \zeta_{\mathrm{m}} \ln \left(\frac{1+\mathrm{e}^{-\kappa \mathrm{y}}}{1-\mathrm{e}^{-\kappa \mathrm{y}}}\right)+\left(\zeta_{\mathrm{f}}^{2}+\zeta_{\mathrm{m}}^{2}\right) \ln \left(1-\mathrm{e}^{-2 \kappa \mathrm{y}}\right)\right]
$$

where $\mathrm{y}(\mathrm{nm})$ is the separation distance between the foulants and membrane surface, $\varepsilon_{\gamma}$ is the relative dielectric constant, $\mathrm{C}^{2} /\left(\mathrm{N} \cdot \mathrm{m}^{2}\right) ; \varepsilon_{0}$ is the vacuum dielectric constant, $\mathrm{C}^{2} /\left(\mathrm{N} \cdot \mathrm{m}^{2}\right)$; $\mathrm{y}_{0}$ is the minimum separation distance between interaction surfaces (usually taken as 0.158 $\mathrm{nm}) ; \zeta$ is the zeta potential; $\kappa$ is the inverse Debye screening length $\left(0.104 \mathrm{~nm}^{-1}\right)$; and $\lambda$ is the decay length of the $\mathrm{AB}$ interaction in water $(0.6 \mathrm{~nm})$.

The interfacial free energy $\Delta \mathrm{G}_{\mathrm{y}_{0}}^{\mathrm{EL}}, \Delta \mathrm{G}_{\mathrm{y}_{0}}^{\mathrm{LW}}$, and $\Delta \mathrm{G}_{\mathrm{y}_{0}}^{\mathrm{AB}}$ are the interaction energy per unit area of EL, LW, and $A B$, respectively, as expressed in $\mathrm{mJ} / \mathrm{m}^{2}$, which can be obtained as follows:

$$
\begin{array}{r}
\Delta \mathrm{G}_{\mathrm{y}_{0}}^{\mathrm{LW}}=-2\left(\sqrt{\gamma_{\mathrm{m}}^{\mathrm{LW}}}-\sqrt{\gamma_{1}^{\mathrm{LW}}}\right)\left(\sqrt{\gamma_{\mathrm{f}}^{\mathrm{LW}}}-\sqrt{\gamma_{\mathrm{l}}^{\mathrm{LW}}}\right) \\
\Delta \mathrm{G}_{\mathrm{y}_{0}}^{\mathrm{AB}}=2\left[\sqrt{\gamma_{1}^{+}}\left(\sqrt{\gamma_{\mathrm{f}}^{-}}+\sqrt{\gamma_{\mathrm{m}}^{-}}-\sqrt{\gamma_{1}^{-}}\right)+\sqrt{\gamma_{1}^{-}}\left(\sqrt{\gamma_{\mathrm{f}}^{+}}+\sqrt{\gamma_{\mathrm{m}}^{+}}-\sqrt{\gamma_{1}^{+}}\right)-\left(\sqrt{\gamma_{\mathrm{f}}^{-} \gamma_{\mathrm{m}}^{+}}+\sqrt{\gamma_{\mathrm{f}}^{+} \gamma_{\mathrm{m}}^{-}}\right)\right]
\end{array}
$$

where $\gamma^{\mathrm{LW}}$ is the van der Waals surface tension component, and $\gamma^{+}$and $\gamma^{-}$are the electron acceptor surface tension component and the electron donor surface tension component, respectively, as expressed in $\mathrm{mJ} / \mathrm{m}^{2}$.

The surface tension parameters $\left(\gamma_{S}^{\mathrm{LW}}, \gamma_{\mathrm{S}}^{+}\right.$, and $\left.\gamma_{\mathrm{S}}^{-}\right)$for the membranes and foulants can be calculated by the extended Young equation given by

$$
\left(\gamma_{\mathrm{L}}^{\mathrm{LW}}+2 \sqrt{\gamma_{\mathrm{L}}^{+} \gamma_{\mathrm{L}}^{-}}\right)(1+\cos \theta)=2\left(\sqrt{\gamma_{\mathrm{S}}^{\mathrm{LW}} \gamma_{\mathrm{L}}^{\mathrm{LW}}}+\sqrt{\gamma_{\mathrm{S}}^{+} \gamma_{\mathrm{L}}^{-}}+\sqrt{\gamma_{\mathrm{S}}^{-} \gamma_{\mathrm{L}}^{+}}\right)
$$

where $\theta$ is the contact angle, and $\gamma_{\mathrm{L}}^{\mathrm{LW}}, \gamma_{\mathrm{L}}^{+}$, and $\gamma_{\mathrm{L}}^{-}$are the known surface tension properties for three probe liquids.

The total surface tension $\gamma^{\mathrm{TOT}}\left(\mathrm{mJ} / \mathrm{m}^{2}\right)$ and the $\mathrm{AB}$ components of surface tension $\left(\mathrm{mJ} / \mathrm{m}^{2}\right)$ are expressed as follows:

$$
\begin{gathered}
\gamma^{\mathrm{TOT}}=\gamma^{\mathrm{AB}}+\gamma^{\mathrm{LW}} \\
\gamma^{\mathrm{AB}}=2 \sqrt{\gamma^{+} \gamma^{-}}
\end{gathered}
$$

\section{Materials and Methods}

\subsection{Materials}

Commercial homogeneous AEMs (SELEMION AMV) and CEMs (SELEMION CMV) were provided by AGC ENGINEERING CO., LTD (Chiba, Japan). The detailed properties of the ion exchange membrane are presented in Table S1. Three natural organic matters such as SA, HA, and BSA were utilized as model foulants and purchased from Sinopharm Chemical Reagent Co., Ltd., Shanghai, China. The stock solutions (0.1 g/L SA, $0.1 \mathrm{~g} / \mathrm{L} \mathrm{HA,}$ and $0.1 \mathrm{~g} / \mathrm{L}$ BSA) were prepared by dissolving the SA, HA, and BSA in pure water, and they had to be mixed for $24 \mathrm{~h}$ to ensure the complete dissolution of foulants. After that, the stock solutions were filtered by glass-fiber membrane $(0.45 \mu \mathrm{m}, \mathrm{GF} / \mathrm{F}$, Whatman, UK). The filtered stock solutions were placed in the refrigerator at $4{ }^{\circ} \mathrm{C}$. Reagent grade salt of $\mathrm{NaCl}$ and $\mathrm{CaCl}_{2}$ (Sinopharm Chemical Reagent Co., Ltd., Shanghai, China) were used to prepare the solutions for fouling experiments. The electrode rinse solution was prepared by adding $\mathrm{Na}_{2} \mathrm{SO}_{4}$ (AR, Sinopharm Chemical Reagent Co., Ltd., Shanghai, China). All solutions were prepared by pure water, which was provided by one standalone water purification system (Yantai Huiquan Equipment Co., Ltd., Yantai, China).

\subsection{Experimental Protocol}

The self-made bench-scale ED apparatus was utilized as presented schematically in Figure S1. It consisted of a membrane stack, a DC power supply (PS-305DM, Longwei Struments (HK) Co., Ltd., Hong Kong, China), and four peristaltic pumps (CXB-30, Wen- 
zhou Erle Pump Co., Ltd., Wenzhou, China). The membrane stack consisted of dilute, concentrated, and electrode compartments, which were separated by three pristine CEMs and two pristine AEMs. The DC power supply was connected to membrane stack through two ruthenium-coated titanium electrodes. The effective area of AEM and CEMs was all $9 \mathrm{~cm}^{2}$ in this work.

During fouling experiments, the $800 \mathrm{~mL}$ initial solution was composed of $10 \mathrm{mmol} / \mathrm{L}$ $\mathrm{NaCl}$ and different foulants (as shown in Table S2) in the dilute compartment and the concentrated compartment. The two compartments were circulated by peristaltic pumps at a flow rate of $150 \mathrm{~mL} / \mathrm{min}$, respectively. The electrode rinse solution was $800 \mathrm{~mL}$ of $0.01 \mathrm{~mol} / \mathrm{L} \mathrm{Na}_{2} \mathrm{SO}_{4}$. Fouling experiments were performed for a continuous period of $20 \mathrm{~h}$ at ambient temperature $\left(20 \pm 0.5^{\circ} \mathrm{C}\right)$. The observation of membrane fouling was carried out under a constant voltage of $3.0 \mathrm{~V}$. Moreover, the conductivity of the dilute compartment solution was measured every $30 \mathrm{~min}$ using a conductivity meter (DDS-307, Shanghai INESA Scientific Instrument Co., Ltd., Shanghai, China). All of the fouling experiments were carried out three times, and the data shown in the paper were the average of the three experiments. It should be noted that the ratios of the fluctuating value to the average were less than $0.1 \%$; thus, the error bars were not added in the figures and tables. After fouling experiments, the used AEMs were rinsed using pure water and then dried naturally or submerged in pure water for further characterization.

\subsection{Characterization Method}

Morphology of the original and used membranes were observed by SEM (Hitachi S4800, Tokyo, Japan) at an accelerating voltage of $10 \mathrm{kV}$ and the magnification of $1.00 \mathrm{k}$. The chemical compositions of membranes were determined using ATR-FTIR Spectrometer (Nicolet 380, Madison, WI, USA). A spectrum collected as the average of 32 scans with a resolution of $4 \mathrm{~cm}^{-1}$ was recorded from 4000 to $400 \mathrm{~cm}^{-1}$. A contact angle meter (Kruss DSA30, Hamburg, Germany) was utilized to measure the contact angles of three probe liquids including ultrapure water, glycerol, and diiodomethane on the original and used membrane surfaces, and the sessile drop method was used in all measurements. The zeta potentials of the original and used AEMs were examined by the zeta potential analyzer (Zeta 90 Plus, Brookhaven Instruments, New York, USA). The zeta potential and particle size distribution of organic colloid were determined by dynamic light scattering with a Zetasizer Nano S90 (ZEN1690, Malvern instruments Ltd., Malvern, UK). For each sample, at least triplicate measurements were carried out in order to ensure the accuracy, and the average values were used in this work. Membranes for SEM, FTIR, and contact angle were dried at $38^{\circ} \mathrm{C}$ for $24 \mathrm{~h}$ before measurements.

\section{Results and Discussion}

\subsection{Influence of SA with Calcium Ions on Membrane Fouling}

Recent studies had demonstrated that divalent cations such as $\mathrm{Ca}^{2+}$ had a dramatic effect on SA fouling in the membrane process $[34,35]$. In the current work, SA with the presence of $\mathrm{Ca}^{2+}$ had been employed as a model foulant to investigate organic fouling in the ED process. Table 1 showed the particle zeta potential, colloid sizes, and interfacial interaction energy in different membrane-SA-calcium ion systems. It could be seen that variations in the interfacial interaction energy were illustrated in different membrane-SAcalcium ion systems, due to differences in $\mathrm{Ca}^{2+}$ concentration. In terms of the xDLVO theory, a positive value for the total interaction energy between membrane and foulants indicated the resistance to membrane fouling, while a negative value means a promotion to membrane fouling $[36,37]$. In all membrane-SA-calcium ion systems, the negative value of the total interaction energy could be inferred that the foulant of SA tended to exacerbate the membrane fouling. Lower interaction energy occurred when calcium ion was absent in the aqueous solution. This demonstrated that calcium ions exhibited a predominant contribution to AEMs fouling. Simultaneously, the total interaction energy between SA and anion exchange membrane firstly increased and then decreased with the increase in 
calcium ion concentration. Similar results were published previously $[38,39]$ and could be explicated by charge neutralization as well as the SA-calcium ionic bridge that formed, which decreased the electrostatic repulsion and increased the attractive energy between SA molecules and the membrane surface. Hence, the total interaction energy changed from -7.7383 to $-22.0968 \mathrm{~mJ} / \mathrm{m}^{2}$, revealing that calcium ions had a very great influence on the membrane fouling by SA.

Table 1. Interaction energy, particle zeta potential, and colloid size in different AEM-SA-Ca ${ }^{2+}$ systems.

\begin{tabular}{ccccccc}
\hline $\begin{array}{c}{\left[\mathbf{C a}^{2+}\right]} \\
/(\mathbf{m m o l})\end{array}$ & $\triangle \mathbf{G}^{\mathbf{L W}}$ & $\triangle \mathbf{G}^{\mathrm{AB}}$ & $\triangle \mathbf{G}^{\mathrm{EL}}$ & $\triangle \mathbf{G}^{\mathrm{TOT}}$ & $\begin{array}{c}\text { Particle Zeta } \\
\text { Potential/mV }\end{array}$ & $\begin{array}{c}\text { Colloid } \\
\text { Size/nm }\end{array}$ \\
\hline 0 & $-4.2392^{\mathrm{a}}$ & -3.3704 & -0.1287 & -7.7383 & -50.45 & 264.2 \\
2 & -4.6799 & -10.6036 & -0.0675 & -15.3510 & -28.9 & 507.3 \\
4 & -4.0827 & -17.9737 & -0.0404 & -22.0968 & -21.96 & 744.6 \\
8 & -4.4170 & -15.3426 & -0.0358 & -19.7954 & -17.54 & 832.8 \\
\hline
\end{tabular}

${ }^{\mathrm{a}}$ Interaction energy per unit $\left(\mathrm{mJ} / \mathrm{m}^{2}\right)$.

As could be seen in Table 1, the particle size of SA increased as the calcium ions increased. The particle size was the smallest in SA solutions without calcium ions, while the maximum particle size occurred at a calcium ion concentration of $8 \mathrm{mmol}$. It was observed that calcium ions could enlarge the particle size of SA due to carboxylic functional groups in SA molecules, which bound them together via calcium ion bridging, leading to the formation of macromolecular chelate $[40,41]$. During the electrodialysis process, the ionic bridge among SA and between SA and the membrane surface with the presence of $\mathrm{Ca}^{2+}$ facilitated the formation of an across-linked organic gel layer on the AEMs surface [42].

The zeta potential is an important parameter that governs the electrostatic interaction between the organic compound and membrane. The addition of calcium ions in aqueous solutions increased the particle zeta potential, and the zeta potential increased with the increasing calcium ion concentration. The shielding effect of calcium ions and complexation of calcium ions with SA functional groups can effectively neutralize the electronegativity of alginate [43], resulting in the particle zeta potential increasing. The zeta potential would reflect the electrostatic forces of mutual exclusion or attraction between particles. The particles tend to condense or agglomerate at a lower zeta potential value (positive or negative) because the attraction exceeds the repulsive force. The important utilization of zeta potential is to investigate the interaction of colloids with electrolytes due to many charged colloids interact with the electrolyte in a complicated manner. In this study, positively charged calcium ions reduced the absolute value of zeta potential and promoted the agglomeration of SA molecules, leading to membrane fouling aggravation. Furthermore, SA would reduce AEMs' hydrophilicity and increase hydrophobicity, which represents an attractive effect to exacerbate membrane fouling [15,44,45].

Figure 1 presented the variation of AEM-SA interaction energy with separation distances between the surface of AEM and SA in different calcium ion concentration solutions. It could be seen that the interaction energy including TOT, LW, AB, and EL gradually closed to a zero value with the increasing of the distance between SA molecules and AEM. The results revealed that the attractive reaction had gradually enhanced, which led to an aggravation of membrane fouling in the presence of calcium ions. As seen in Figure 1, the total interaction energy curve was steepest at $4 \mathrm{mmol} / \mathrm{L}$ calcium ion concentration. It was inferred that the $\mathrm{U}^{\mathrm{AB}}$ made the dominant contribution to the $\mathrm{U}^{\mathrm{TOT}}$ (corresponding to $\mathrm{U}^{\mathrm{xDLVO}}$ ) when the separation distance was less than $5 \mathrm{~nm}$ with the presence of calcium ions. Among them, AB was mostly affected by calcium ions; it is typical for Lewis acid to act as an electron acceptor. Moreover, calcium ions would increase the surface tension parameters of the Lewis acid/base further to increase the magnitude of $U^{A B}$ determined by the surface tension parameters of the Lewis acid/base, which was proven in the previously reported study [46-48]. 


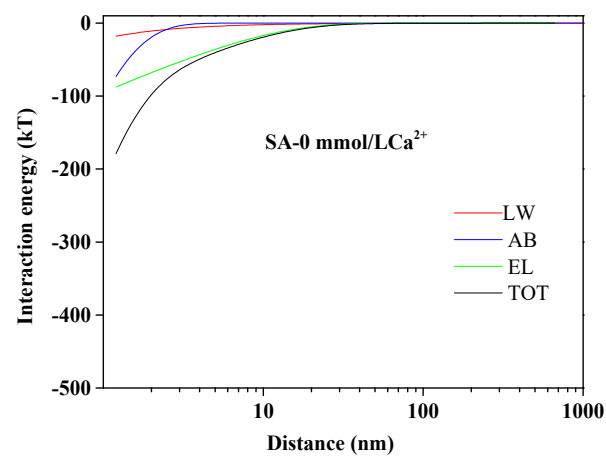

(a)

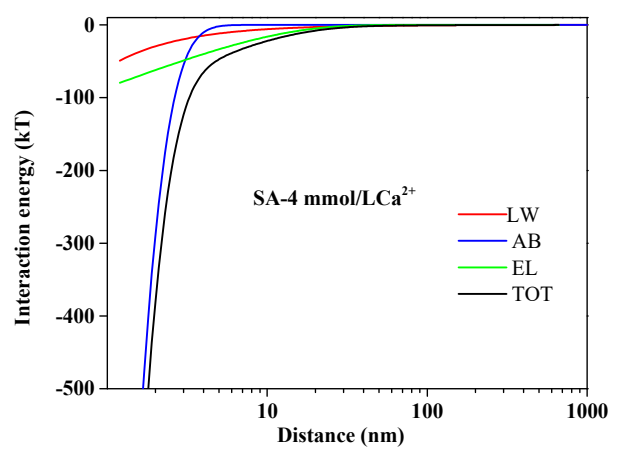

(c)

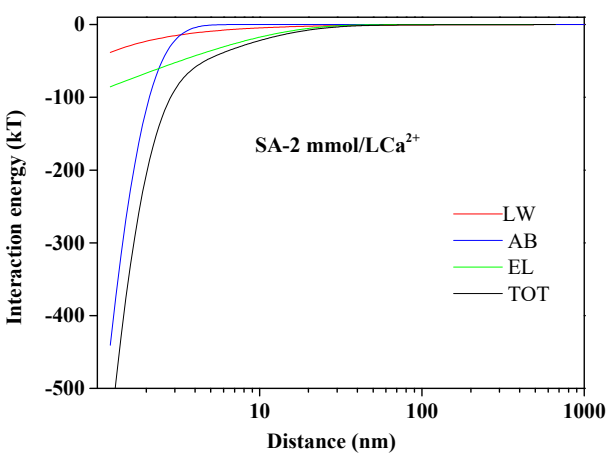

(b)

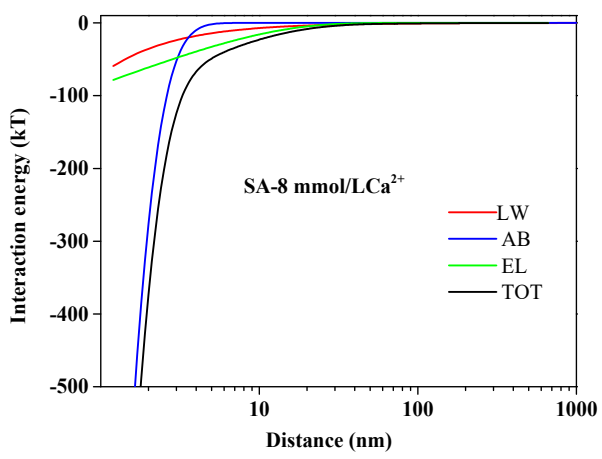

(d)

Figure 1. Variation of AEM-SA interaction energy profiles at different calcium ion concentrations: (a) SA without $\mathrm{Ca}^{2+}$; (b) SA with $2 \mathrm{mmol} / \mathrm{L} \mathrm{Ca}^{2+}$; (c) SA with $4 \mathrm{mmol} / \mathrm{L} \mathrm{Ca}^{2+}$; (d) SA with $8 \mathrm{mmol} / \mathrm{L} \mathrm{Ca}^{2+}$.

The FTIR spectrum and SEM images of the original and used membrane are shown in Figure 2 and Figure S2. From the FTIR spectrum of the virgin membrane, it could be that the peak at $3300-3100 \mathrm{~cm}^{-1}$ was a specific peak of $\mathrm{C}-\mathrm{H}$ in the benzene ring; and the peaks around $1580 \mathrm{~cm}^{-1}$ and $1480 \mathrm{~cm}^{-1}$ are characteristic absorption peaks of the benzene ring skeleton; besides, there is a peak around $2923 \mathrm{~cm}^{-1}$, which was the peak of $-\mathrm{CH}_{3}$. For the membrane after SA with $\mathrm{Ca}^{2+}$ fouling, there is a distinct broad peak at $3500-3100 \mathrm{~cm}^{-1}$ in the FTIR spectrum. Compared with the original membrane, this peak shape was wider. This was the effect of the influence of the stretching vibration of the associated -OH. A new characteristic peak occurred at around $1650 \mathrm{~cm}^{-1}$, which corresponded to a $\mathrm{C}=\mathrm{O}$ bond. The peak of the C-H bond was located near $2924 \mathrm{~cm}^{-1}$. It indicated the adhesion of SA on the anion exchange membrane. Additionally, with the presence of a calcium ion, the strong foulant-foulant attractive interaction would accelerate the formation of a compact gel layer of SA on the membrane surface, which resulted in the more severe fouling of AEMs. This was verified by the SEM images of the membrane surface, as shown in Figure 2. For example, the membrane surfaces were contaminated by foulants and gradually formed a dense gel layer with the absence and presence of calcium ion (Figure 2). 


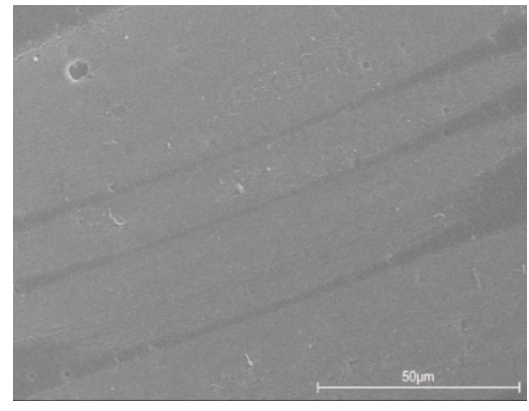

Original membrane

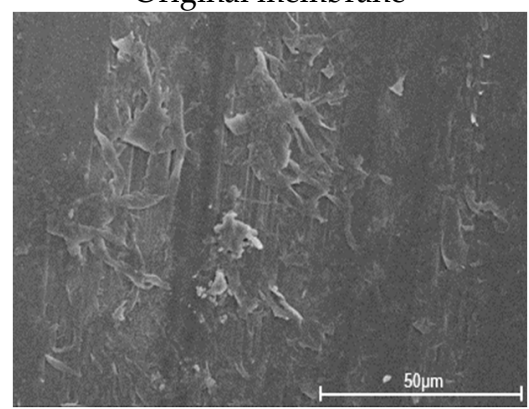

AEM-SA-4 mmol Ca ${ }^{2+}$

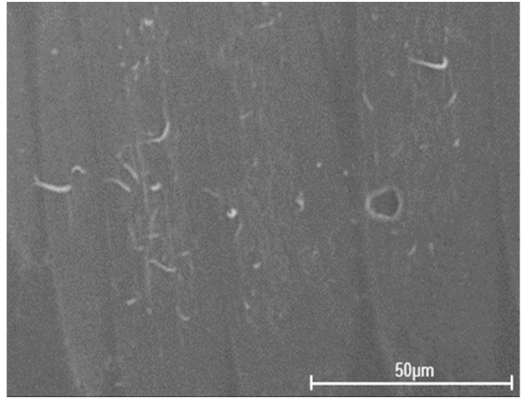

AEM-SA-0 mmol Ca ${ }^{2+}$

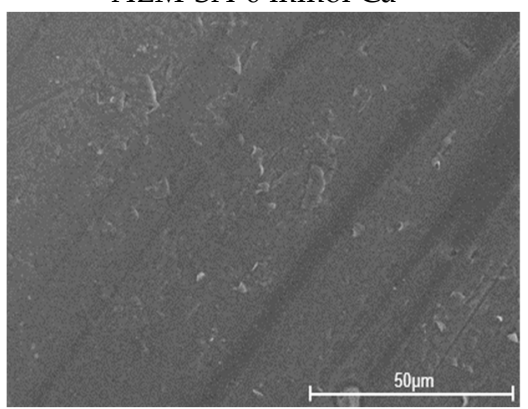

AEM-SA-8 mmol Ca ${ }^{2+}$

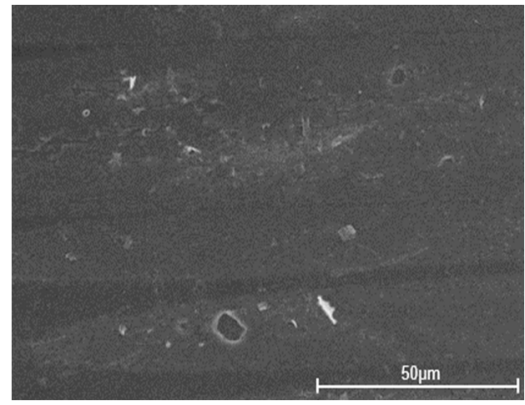

AEM-SA-2 mmol Ca ${ }^{2+}$

Figure 2. SEM images of original and used AEMs in the AEM-SA system with different calcium ion concentrations.

\subsection{Influence of HA with Calcium Ions on Membrane Fouling}

In the case of $\mathrm{HA}$ with the absence and presence of $\mathrm{Ca}^{2+}$ fouling, the variation of the particle zeta potential, the colloid size, and the interfacial energy between HA and the anion exchange membrane are presented in Table 2. It could be seen that calcium ions have made a difference in the AEM-HA interaction energy. Based on the xDLVO theory, the presence of calcium ions could deteriorate membrane fouling. Moreover, the membrane fouling of HA to AEM was aggravated as the $\mathrm{Ca}^{2+}$ concentrations increased, and the most serious fouling of AEM occurred at a calcium ion concentration of $8 \mathrm{mmol} / \mathrm{L}$.

Table 2. Interaction energy, particle zeta potential, and colloid size indifferent AEM-HA-Ca ${ }^{2+}$ systems.

\begin{tabular}{ccccccc}
\hline $\begin{array}{c}{\left[\mathbf{C a}^{2+}\right]} \\
/(\mathbf{m m o l})\end{array}$ & $\triangle \mathbf{G}^{\mathbf{L W}}$ & $\triangle \mathbf{G}^{\mathbf{A B}}$ & $\triangle \mathbf{G}^{\mathrm{EL}}$ & $\triangle \mathbf{G}^{\mathrm{TOT}}$ & $\begin{array}{c}\text { Particle Zeta } \\
\text { Potential/m }\end{array}$ & $\begin{array}{c}\text { Colloid } \\
\text { Size/nm }\end{array}$ \\
\hline 0 & -5.0024 & 0.8008 & -0.1369 & -4.3385 & -55.66 & 285.9 \\
2 & -5.6135 & -0.0421 & -0.0812 & -5.7368 & -38.12 & 472.5 \\
4 & -5.5391 & -7.7161 & -0.0449 & -13.3001 & -24.75 & 533.3 \\
8 & -5.4103 & -13.1170 & -0.0352 & -18.5625 & -20.07 & 596.4 \\
\hline
\end{tabular}

As shown in Table 2, changes in the zeta potential and colloidal size of HA particles indicated that the concentration of calcium ions had a dominant effect on HA characteristics because HA had a more negative charge than SA. Zeta potentials varied from $-55.66 \mathrm{mV}$ to $-20.07 \mathrm{mV}$ with the increasing $\mathrm{Ca}^{2+}$ concentrations because the complexation of carboxyl groups with $\mathrm{Ca}^{2+}$ neutralized the electronegativity of HAs. In addition, the colloid size of HA changed from 285.9 to $596.4 \mathrm{~nm}$ due to the reducing of electrostatic repulsion between HA molecules, which was conducive to the aggregation of HA colloidal particles. Moreover, the bridging between $\mathrm{Ca}^{2+}$ and HA macromolecules accelerates the increasing colloid size of HA particles, which were liable to adhere on the surface of AEMs, deteriorating membrane fouling.

The HA fouling process was determined by the mutual interactions between AEM and HA and among HA molecules. The quantitative evaluations of these interactions could be acquired by the XDLVO theory. The calculated total interaction energy with different $\mathrm{Ca}^{2+}$ concentrations is also presented in Table 2 . It could be observed that the 
total interaction energy was enhanced from -4.3385 to $-18.5625 \mathrm{~mJ} / \mathrm{m}^{2}$ with increasing $\mathrm{Ca}^{2+}$ concentrations, indicating that $\mathrm{Ca}^{2+}$ played a significant role in the total interaction energy. To further explore the influencing mechanism of interactions on membrane fouling, the interaction energy at different separation distances between the membrane surface and HA in different $\mathrm{Ca}^{2+}$ concentrations is illustrated in Figure 3. As shown in Figure 3, the positive $A B$ interaction energy increased slightly as the distance of HA to AEM decreased in the absence of $\mathrm{Ca}^{2+}$. Nevertheless, the values of LW, EL, and TOT interaction energy were all negative and had minor variations as the distance of HA to AEM decreased without $\mathrm{Ca}^{2+}$. With the addition of calcium ions, the value of $\mathrm{AB}$ became negative, and its curve became steeper with the calcium ions concentration increasing. The TOT interaction energy curve trend was similar to that of $\mathrm{AB}$. It could be revealed that the $\mathrm{AB}$ interaction energy accounted for the main proportion of total interaction energy, while the interaction energy of LW and EL had a small impact on the energy of TOT interaction. The negative interaction energy decreased as the distance of HA to AEM decreased in the presence of $\mathrm{Ca}^{2+}$, which indicated an adhesive reaction enhanced between HA and AEMs leading to severe membrane fouling.

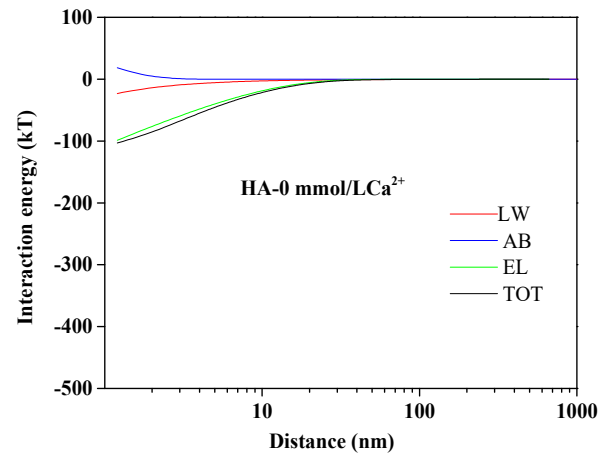

(a)

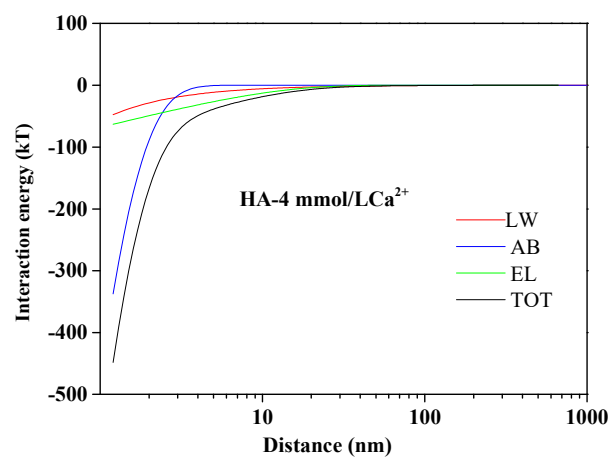

(c)

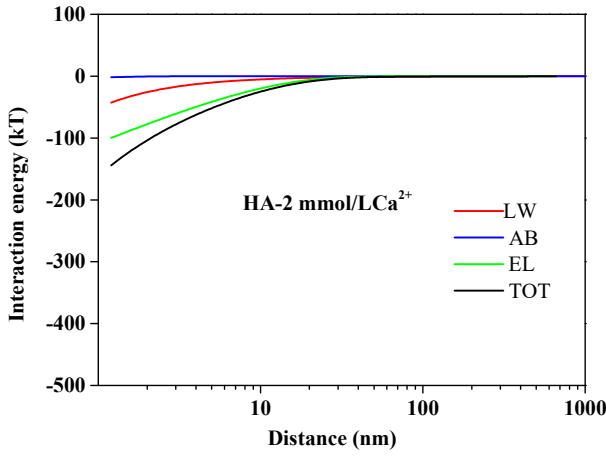

(b)

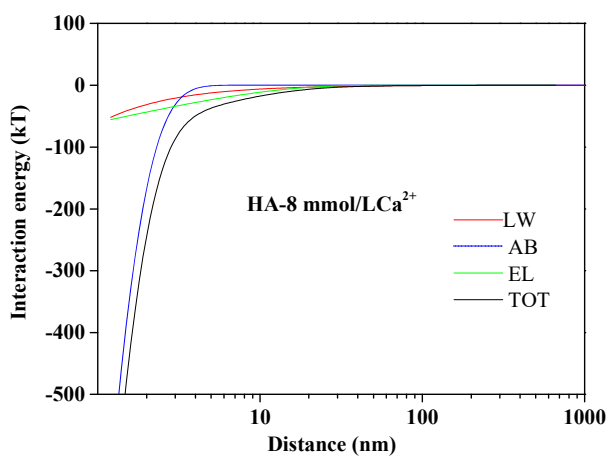

(d)

Figure 3. Variation of AEM-HA interaction energy profiles at different calcium ion concentrations: (a) $\mathrm{HA}$ without $\mathrm{Ca}^{2+}$; (b) $\mathrm{HA}$ with $2 \mathrm{mmol} / \mathrm{L} \mathrm{Ca}^{2+}$; (c) $\mathrm{HA}$ with $4 \mathrm{mmol} / \mathrm{L} \mathrm{Ca}^{2+}$; (d) $\mathrm{HA}$ with $8 \mathrm{mmol} / \mathrm{L} \mathrm{Ca}^{2+}$.

Comparing the FTIR spectra of original and the used membrane by HA together with $4 \mathrm{mmol} \mathrm{Ca}{ }^{2+}$, as shown in Figure S3, a broad adsorption peak at $3400 \mathrm{~cm}^{-1}$ was attributed to the overlapping of bands from the stretching vibrations of $\mathrm{N}-\mathrm{H}$ and $\mathrm{O}-\mathrm{H}$, which revealed the presence of HA. Moreover, the characteristic bands of HA such as $\mathrm{C}=\mathrm{O}$ stretching vibration, $\mathrm{C}-\mathrm{N}$ stretching vibration, and $\mathrm{C}-\mathrm{O}$ stretching vibration were assigned at $1610 \mathrm{~cm}^{-1}, 1444 \mathrm{~cm}^{-1}$, and $1093 \mathrm{~cm}^{-1}$, respectively. Meanwhile, the representative bands of used AEM such as C-H bending vibration at $1376 \mathrm{~cm}^{-1}$ respond at a lower wavenumber. A lower wavenumber denotes the increase in the bond length, and this might be attributed to the electrostatic and affinity interaction between HA and AEM [18,49,50]. 
Figure 4 presented the surface morphology of the different used AEMs in feed solutions containing $0.1 \mathrm{~g} / \mathrm{L}$ HA with and without $\mathrm{Ca}^{2+}$. Comparison of these images indicated that the concentration of $\mathrm{Ca}^{2+}$ played a significant role in AEMs fouling. With the ED process performed, more $\mathrm{HA}-\mathrm{Ca}^{2+}$ complex generated and accumulated onto the AEMs surface, which could form a denser gel layer on the AEMs surface. It could be verified that the charge and hydrophilic characteristics of HA was reduced significantly due to the $\mathrm{HA}-\mathrm{Ca}^{2+}$ complex formation in the presence of $\mathrm{Ca}^{2+}$. However, regardless of the particle size or total interaction energy, the contribution of $\mathrm{Ca}^{2+}$ in HA to AEM fouling was less than that of SA. It was revealed that $\mathrm{Ca}^{2+}$ combines specifically with carboxylic groups of SA as well as serving as a bridge between adjacent SA molecules, resulting in a more compact gel layer than those formed in the case of HA $[47,50,51]$.

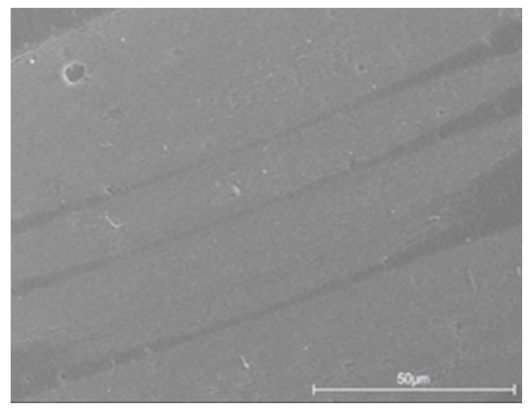

Original membrane

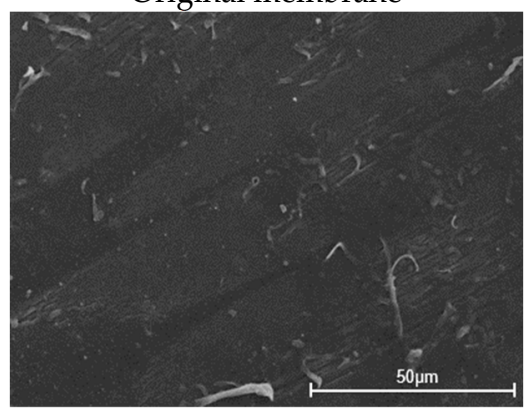

AEM-HA-4 mmol Ca'+

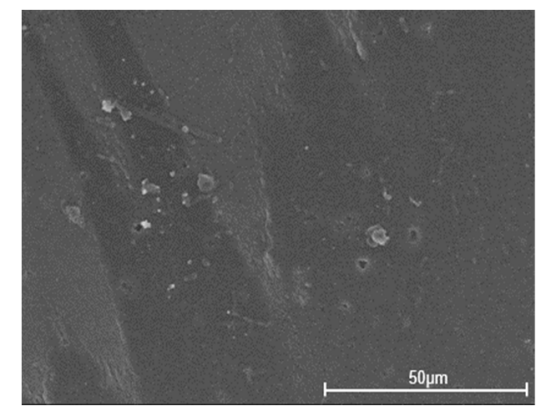

AEM-HA-0 mmol Ca ${ }^{2+}$

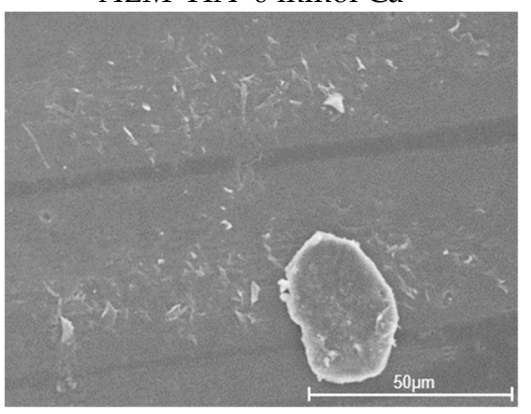

AEM-HA-8 mmol Ca2+

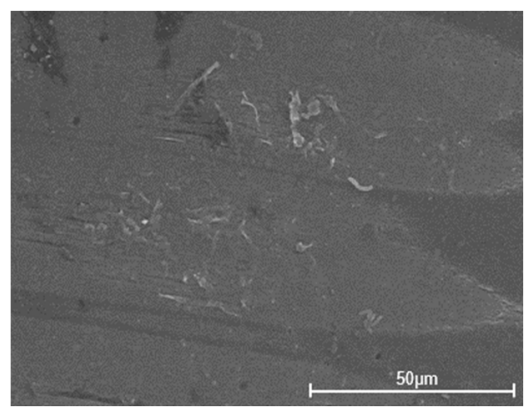

AEM-HA-2 mmol Ca ${ }^{2+}$

Figure 4. SEM images of original and used AEMs in AEM-HA system with different calcium ion concentration.

\subsection{Influence of BSA with Calcium Ions on Membrane Fouling}

Variations in the interaction energy of each AEM-BSA-Ca ${ }^{2+}$ system are summarized in Table 3. The total interaction energy in different AEM-BSA-Ca ${ }^{2+}$ systems had negative value, indicating a higher attractive effect. As illustrated in Table $3, \mathrm{Ca}^{2+}$ concentration played a dominant role in the total interaction energy, zeta potential, and colloid size in case of BSA. The total interaction energy decreased from -11.2046 to $-20.5718 \mathrm{~mJ} / \mathrm{m}^{2}$ as the $\mathrm{Ca}^{2+}$ concentration increased. However, compared with SA and HA, the influence of $\mathrm{Ca}^{2+}$ concentrations on the total interaction energy, zeta potential, and colloid size became less substantial in different AEM-BSA-Ca ${ }^{2+}$ systems. It was possible that BSA molecules have a lower density of $-\mathrm{COO}^{-}$functional groups and thus have a weaker calcium ion bridging effect. In accordance with our study, Gao et al. also discovered the inconspicuous complexation of BSA with calcium ions [52]. Moreover, the size of the BSA colloid increased slightly with increasing $\mathrm{Ca}^{2+}$ concentrations, only increased from 364.5 to $548.5 \mathrm{~nm}$. It was further inferred that there was an insignificant bridging effect between BSA molecules and calcium ions. Additionally, the zeta potential of particles could influence membrane fouling, which was dependent on the total interaction energy. As shown in Table 3, the zeta potential of particles increased with increasing $\mathrm{Ca}^{2+}$ concentrations. It was observed that with the increase in $\mathrm{Ca}^{2+}$ concentrations, the compression of the electric double layer because of the charge shielding effect reduced the electrostatic repulsion among BSA molecules. This was 
beneficial to the coagulation between BSA molecules and accelerated the formation of a gel layer on the AEMs surface. Nevertheless, the experiment results presented in Table 3 indicated that the effect of BSA colloid size on membrane fouling is more significant than that of the zeta potential, which could be inferred from Equations (2)-(4).

Table 3. Interaction energy, particle zeta potential, and colloid size-indifferent AEM-BSA-Ca ${ }^{2+}$ systems.

\begin{tabular}{ccccccc}
\hline $\begin{array}{c}{\left[\mathbf{C a}^{2+}\right]} \\
/(\mathbf{m m o l})\end{array}$ & $\triangle \mathbf{G}^{\mathbf{L W}}$ & $\triangle \mathbf{G}^{\mathbf{A B}}$ & $\triangle \mathbf{G}^{\mathrm{EL}}$ & $\triangle \mathbf{G}^{\mathrm{TOT}}$ & $\begin{array}{c}\text { Particle Zeta } \\
\text { Potential/mV }\end{array}$ & $\begin{array}{c}\text { Colloid } \\
\text { Size/nm }\end{array}$ \\
\hline 0 & -5.2535 & -5.8564 & -0.0969 & -11.2046 & -42.65 & 364.5 \\
2 & -5.3028 & -9.9250 & -0.0508 & -15.2786 & -25.31 & 432.7 \\
4 & -5.3231 & -13.5620 & -0.0403 & -18.9254 & -21.43 & 510.2 \\
8 & -5.4067 & -15.1302 & -0.0349 & -20.5718 & -19.92 & 548.5 \\
\hline
\end{tabular}

The results of interaction energy profiles at different $\mathrm{Ca}^{2+}$ concentrations are illustrated in Figure 5. It is well known that membrane fouling relied on the total interaction energy, including $\mathrm{AB}, \mathrm{LW}$, and $\mathrm{EL}$ interaction energy. With the increase in $\mathrm{Ca}^{2+}$ concentrations, the TOT interaction energy curve became steeper, indicating that the adhesive reaction became stronger, thus aggravating membrane fouling. Figure 5 also clearly manifested that the value of $\mathrm{U}^{\mathrm{AB}}$ approached zero when the distance from the BSA particles to the membrane surface was greater than $10 \mathrm{~nm}$, but the $\mathrm{U}^{\mathrm{AB}}$ played a predominant role in short-distance separation. Therefore, the reduction of $\mathrm{U}^{\mathrm{AB}}$ was beneficial to alleviate membrane fouling.

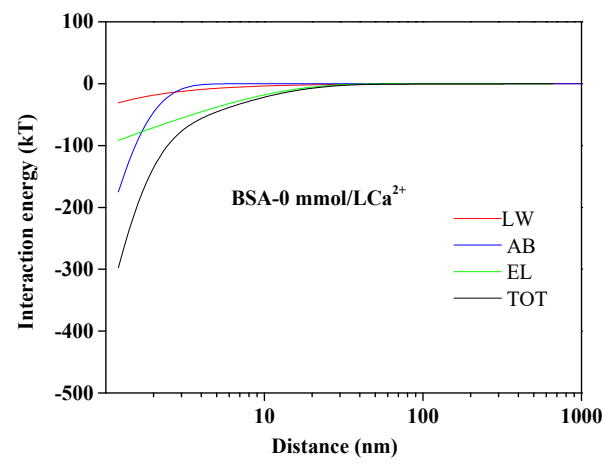

(a)

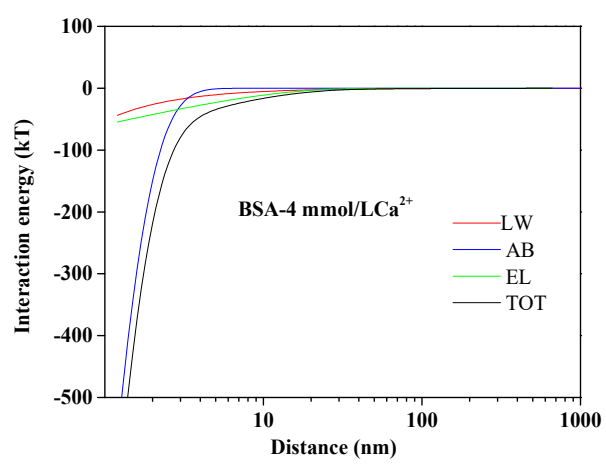

(c)

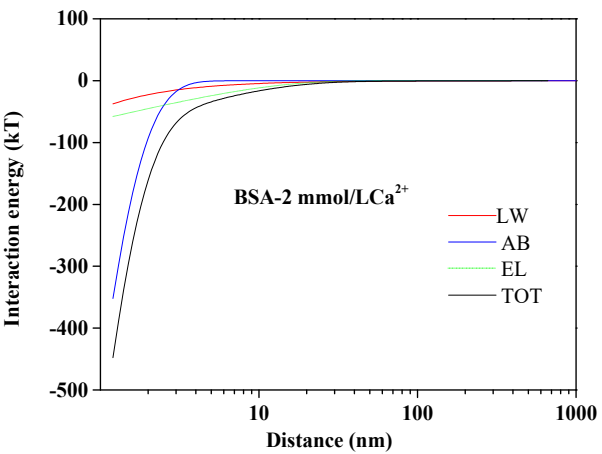

(b)

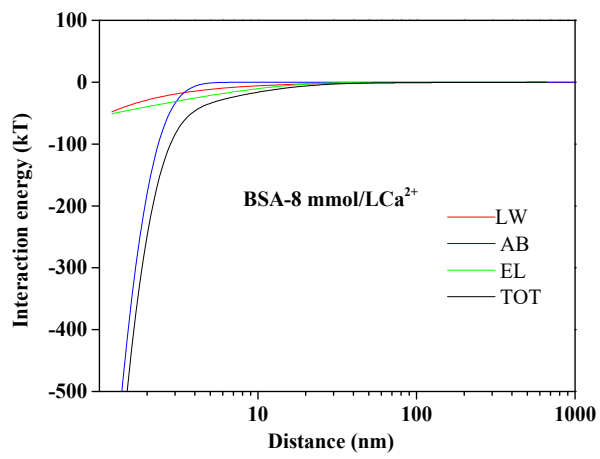

(d)

Figure 5. Variation of AEM-BSA interaction energy profiles at different calcium ion concentrations: (a) BSA without Ca ${ }^{2+}$; (b) BSA with $2 \mathrm{mmol} / \mathrm{L} \mathrm{Ca}^{2+}$; (c) BSA with $4 \mathrm{mmol} / \mathrm{L} \mathrm{Ca}^{2+}$; (d) BSA with $8 \mathrm{mmol} / \mathrm{L} \mathrm{Ca}^{2+}$.

The FITR and SEM were employed to characterize AEMs fouled by the different BSA-Ca ${ }^{2+}$ systems (Figure 6 and Figure S4). As shown in Figure S4, the absorption peak near $1720 \mathrm{~cm}^{-1}$ marked the presence of $\mathrm{C}=\mathrm{O}$ in the amino compound for the protein-like 
materials. Additionally, the characteristic peaks of $1656 \mathrm{~cm}^{-1}$ and $1643 \mathrm{~cm}^{-1}$ were observed on the BSA fouled membranes surface, indicating the presence of amide I. Moreover, the peak at $1535 \mathrm{~cm}^{-1}$ was exhibited in the FTIR spectra of the BSA fouled membrane, which was attributed to the presence of amide II. As seen from Figure 6, the BSA foulant layer was relatively loose, and the membrane fouling in case of BSA aggravated slightly as the concentration of $\mathrm{Ca}^{2+}$ increased compared with that of SA and HA. It was because the BSA molecules interacted with $\mathrm{Ca}^{2+}$; unlike SA and HA molecules, it was difficult to generate a gel-type fouling layer on the AEM surface [53]. The gel layer forming of SA resulted from the stronger attractive energy and weaker repulsive energy with SA than that of BSA, where the intermolecular interaction needed to be strong enough to maintain the integrity of the gel layer structure. It could be concluded that there was a much slighter difference of decreased attractive $\mathrm{AB}$ energy and LW energy with the increasing of $\mathrm{Ca}^{2+}$ concentrations in the case of BSA than that of SA. The results indicated that the interaction energy is a significant factor for evaluating the tendency of AEMs fouling by natural organic matter.

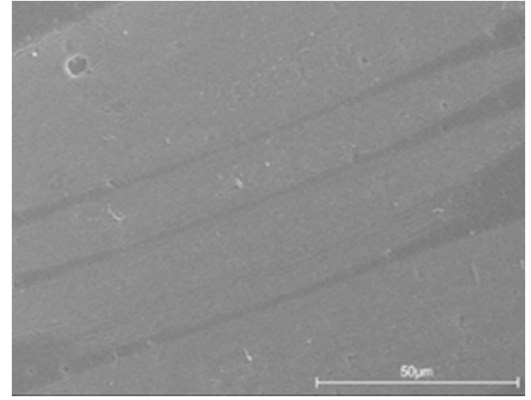

Original membrane

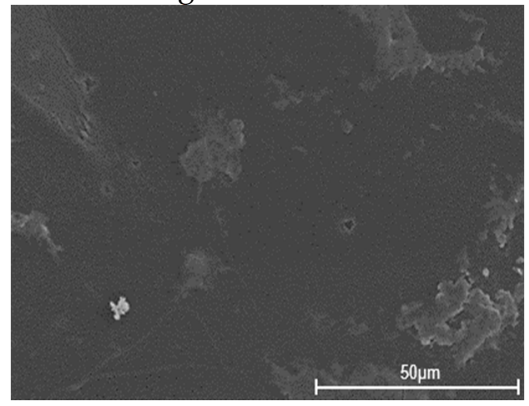

AEM-BSA-4 mmol Ca ${ }^{2+}$

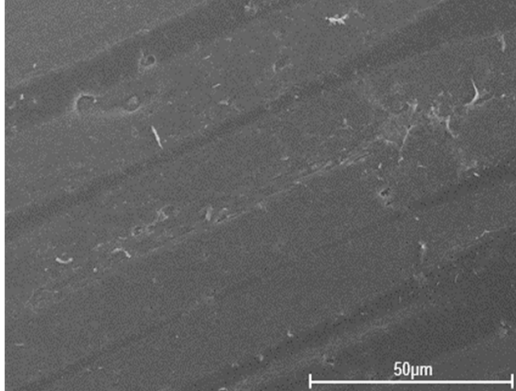

AEM-BSA-0 mmol Ca ${ }^{2+}$

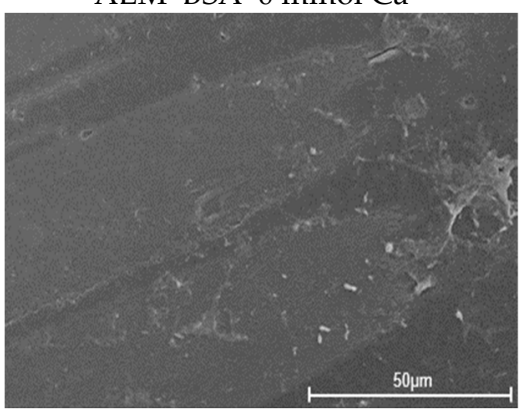

AEM-BSA-8 mmol Ca ${ }^{2+}$

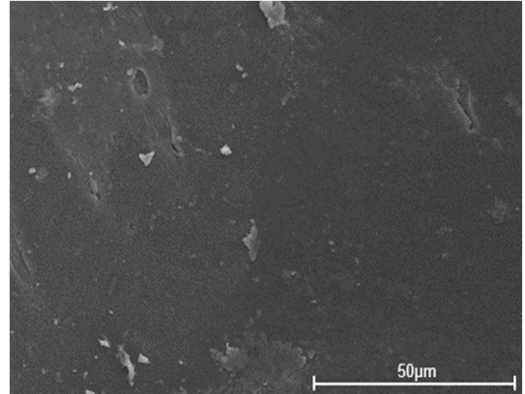

AEM-BSA-2 mmol Ca ${ }^{2+}$

Figure 6. SEM images of original and used AEMs in the AEM-SA system with different calcium ion concentration.

\section{Conclusions}

In the present study, the organic fouling mechanism of AEMs in the ED process was elucidated by xDLVO theory, using SA, HA, and BSA with and without $\mathrm{Ca}^{2+}$ as model foulants. The contributions of LW interactions, EL interactions, as well as AB interactions to the total interaction energy that resulted from NOM fractions attaching to the AEMs surface were evaluated. It was worth noting that the short-range acid-base interactions accounted for a more predominating contribution than the van der Waals interactions to the total interaction energy, which played a dominant role in membrane fouling. However, the influence of electrostatic interactions on AEM fouling was negligible due to the slight contribution to the total interaction energy. Meanwhile, ionic bridging between NOM components with the presence of calcium ions resulted in the formation of a complex on the membrane surface, which produced a compact gel layer and tremendously deteriorate anion exchange membrane fouling. These results revealed that the xDLVO theory was a promising strategy to predict and elucidate the NOM fouling of AEMs during the ED process. 
Supplementary Materials: The following are available online at https:/ /www.mdpi.com/article/10 .3390/membranes11120968/s1, Figure S1: The schematic diagram of the experiment; Figure S2: FTIR spectrum of virgin membrane and fouled membrane by SA together with $4 \mathrm{mmol} \mathrm{Ca}^{2+}$; Figure S3: FTIR spectrum of fouled membrane by HA together with $4 \mathrm{mmol} \mathrm{Ca}^{2+}$; Figure S4: FTIR spectrum of fouled membrane by BSA together with $4 \mathrm{mmol} \mathrm{Ca}{ }^{2+}$; Table S1: Properties of ion exchange membranes; Table S2: Concentration of foulants used in the fouling experiments in ED process.

Author Contributions: Conceptualization, Z.M. and X.J.; methodology, Z.M. and Q.W.; software, L.Z.; validation, L.Z. and Y.X.; formal analysis, X.W.; investigation, L.Z. and Y.L.; resources, J.W. and X.G.; data curation, L.Z.; writing-original draft preparation, L.Z. and Y.X.; writing-review and editing, Z.M. and Q.W.; visualization, Y.S.; supervision, Z.M.; project administration, J.X.; funding acquisition, Z.M. and X.G. All authors have read and agreed to the published version of the manuscript.

Funding: This work was financially supported by the Shandong Provincial Natural Science Foundation (No. ZR2020MB118 and No. ZR2020QB175), State Key Laboratory of High-efficiency Utilization of Coal and Green Chemical Engineering(No. 2022-K10), the National Natural Science Foundation of China (No. 22008143), the Qingchuang Science and Technology Program of Shandong Province University (No. 2019KJD004), and Young Taishan Scholars Program of Shandong Province.

Institutional Review Board Statement: Not applicable.

Conflicts of Interest: The authors declare no conflict of interest.

\section{Nomenclature}

\begin{tabular}{|c|c|}
\hline $\mathrm{y}$ & closest distance between a particle and a planar surface (nm) \\
\hline $\mathrm{a}_{\mathrm{C}}$ & radius of foulant particle $(\mathrm{nm})$ \\
\hline $\mathrm{e}$ & electron charge $\left(1.6 \times 10^{-19} \mathrm{C}\right)$ \\
\hline $\mathrm{k}$ & Boltzmann's constant $\left(1.38 \times 10^{-23} \mathrm{~J} \mathrm{~K}^{-1}\right)$ \\
\hline $\mathrm{U}$ & interaction energy between the colloid and membrane surface $\left(\mathrm{mJ} / \mathrm{m}^{-2}\right)$ \\
\hline$\triangle G$ & interaction energy per unit area $\left(\mathrm{mJ} / \mathrm{m}^{-2}\right)$ \\
\hline SA & sodium alginate \\
\hline BSA & bovine serum albumin \\
\hline \multicolumn{2}{|c|}{ Greek letters } \\
\hline$\varepsilon_{0}$ & vacuum dielectric constant, $\mathrm{C}^{2} /\left(N \cdot \mathrm{m}^{2}\right)$ \\
\hline$\varepsilon_{\mathrm{r}}$ & relative dielectric constant, $\mathrm{C}^{2} /\left(N \cdot \mathrm{m}^{2}\right)$ \\
\hline$\gamma$ & surface tension parameter $\left(\mathrm{mJ} / \mathrm{m}^{-2}\right)$ \\
\hline$\zeta$ & zeta potential (mV) \\
\hline K & inverse Debye screening length $\left(0.104 \mathrm{~nm}^{-1}\right)$ \\
\hline$\lambda$ & decay length of $A B$ interaction in water $(0.6 \mathrm{~nm})$ \\
\hline \multicolumn{2}{|c|}{ Superscripts } \\
\hline $\mathrm{AB}$ & short-ranged acid-base \\
\hline EL & electrostatic \\
\hline LW & van der Waals \\
\hline TOT & total \\
\hline+ & electron acceptor \\
\hline- & electron donor \\
\hline \multicolumn{2}{|c|}{ Subscripts } \\
\hline $\mathrm{f}$ & foulant particle \\
\hline 1 & liquid \\
\hline $\mathrm{m}$ & membrane \\
\hline $\mathrm{y}_{0}$ & closest separation distance between interaction surfaces $(0.158 \mathrm{~nm})$ \\
\hline
\end{tabular}

\section{References}

1. Belkada, F.D.; Kitous, O.; Drouiche, N.; Aoudj, S.; Bouchelaghem, O.; Abdi, N.; Grib, H.; Mameri, N. Electrodialysis for fluoride and nitrate removal from synthesized photovoltaic industry wastewater. Sep. Purif. Technol. 2018, 204, 108-115. [CrossRef]

2. Alam, M.; Hossain, M.; Mei, Y.; Jiang, C.; Wang, Y.; Tang, C.Y.; Xu, T. An alkaline stable anion exchange membrane for electro-desalination. Desalination 2021, 497, 114779. [CrossRef] 
3. Afsar, N.U.; Ji, W.; Wu, B.; Shehzad, M.A.; Ge, L.; Xu, T. SPPO-based cation exchange membranes with a positively charged layer for cation fractionation. Desalination 2019, 472, 114145. [CrossRef]

4. Merkel, A.; Voropaeva, D.; Fárová, H.; Yaroslavtsev, A. High effective electrodialytic whey desalination at high temperature. Int. Dairy J. 2020, 108, 104737. [CrossRef]

5. Khan, M.I.; Zheng, C.; Mondal, A.N.; Hossain, M.; Wu, B.; Emmanuel, K.; Wu, L.; Xu, T. Preparation of anion exchange membranes from BPPO and dimethylethanolamine for electrodialysis. Desalination 2017, 402, 10-18. [CrossRef]

6. Wang, X.; Li, N.; Li, J.; Feng, J.; Ma, Z.; Xu, Y.; Sun, Y.; Xu, D.; Wang, J.; Gao, X.; et al. Fluoride removal from secondary effluent of the graphite industry using electrodialysis: Optimization with response surface methodology. Front. Environ. Sci. Eng. 2019, 13, 51. [CrossRef]

7. Khan, M.I.; Mondal, A.N.; Tong, B.; Jiang, C.; Emmanuel, K.; Yang, Z.; Wu, L.; Xu, T. Development of BPPO-based anion exchange membranes for electrodialysis desalination applications. Desalination 2016, 391, 61-68. [CrossRef]

8. Abou-Shady, A. Recycling of polluted wastewater for agriculture purpose using electrodialysis: Perspective for large scale application. Chem. Eng. J. 2017, 323, 1-18. [CrossRef]

9. Suwal, S.; Doyen, A.; Bazinet, L. Characterization of protein, peptide and amino acid fouling on ion-exchange and filtration membranes: Review of current and recently developed methods. J. Membr. Sci. 2015, 496, 267-283. [CrossRef]

10. Persico, M.; Mikhaylin, S.; Doyen, A.; Firdaous, L.; Nikonenko, V.; Pismenskaya, N.; Bazinet, L. Prevention of peptide fouling on ion-exchange membranes during electrodialysis in overlimiting conditions. J. Membr. Sci. 2017, 543, 212-221. [CrossRef]

11. Ruiz, B.; Sistat, P.; Huguet, P.; Pourcelly, G.; Arayafarias, M.; Bazinet, L. Application of relaxation periods during electrodialysis of a casein solution: Impact on anion-exchange membrane fouling. J. Membr. Sci. 2007, 287, 41-50. [CrossRef]

12. Merkel, A.; Ashrafi, A.M.; Ečer, J. Bipolar membrane electrodialysis assisted pH correction of milk whey. J. Membr. Sci. 2018, 555, 185-196. [CrossRef]

13. Sun, Y.; Li, J.; Li, M.; Ma, Z.; Wang, X.; Wang, Q.; Wang, X.; Xu, D.; Gao, J.; Gao, X. Towards improved hydrodynamics of the electrodialysis (ED) cell via computational fluid dynamics and cost estimation model: Effects of spacer parameters. Sep. Purif. Technol. 2020, 254, 117599. [CrossRef]

14. Chang, D.; Choo, K.; Jung, J.; Jiang, L.; Ahn, J.; Nam, M.; Kim, E.; Jeong, S. Foulant identification and fouling control with iron oxide adsorption in electrodialysis for the desalination of secondary effluent. Desalination 2009, 236, 152-159. [CrossRef]

15. Wang, W.; Fu, R.; Liu, Z.; Wang, H. Low-resistance anti-fouling ion exchange membranes fouled by organic foulants in electrodialysis. Desalination 2017, 417, 1-8. [CrossRef]

16. Tanaka, N.; Nagase, M.; Higa, M. Organic fouling behavior of commercially available hydrocarbon-based anion-exchange membranes by various organic-fouling substances. Desalination 2012, 296, 81-86. [CrossRef]

17. Mikhaylin, S.; Bazinet, L. Fouling on ion-exchange membranes: Classification, characterization and strategies of prevention and control. Adv. Colloid Interface Sci. 2016, 229, 34-56. [CrossRef]

18. Guo, H.; Xiao, L.; Yu, S.; Yang, H.; Hu, J.; Liu, G.; Tang, Y. Analysis of anion exchange membrane fouling mechanism caused by anion polyacrylamide in electrodialysis. Desalination 2014, 346, 46-53. [CrossRef]

19. Xie, H.; Pan, J.; Wei, B.; Feng, J.; Liao, S.; Li, X.; Yu, Y. Anti-fouling anion exchange membrane for electrodialysis fabricated by in-situ interpenetration of the ionomer to gradient cross-linked network of Ca-Na alginate. Desalination 2021, 505, 115005. [CrossRef]

20. Berkessa, Y.W.; Lang, Q.; Yan, B.; Kuang, S.; Mao, D.; Shu, L.; Zhang, Y. Anion exchange membrane organic fouling and mitigation in salt valorization process from high salinity textile wastewater by bipolar membrane electrodialysis. Desalination 2019,465 , 94-103. [CrossRef]

21. Zhong, S.; Wu, W.; Wei, B.; Feng, J.; Liao, S.; Li, X.; Yu, Y. Influence of the ions distribution of anion-exchange membranes on electrodialysis. Desalination 2018, 437, 34-44. [CrossRef]

22. Mo, H.; Tay, K.G.; Ng, H.Y. Fouling of reverse osmosis membrane by protein (BSA): Effects of pH, calcium, magnesium, ionic strength and temperature. J. Membr. Sci. 2008, 315, 28-35. [CrossRef]

23. Lee, H.-J.; Hong, M.-K.; Han, S.-D.; Cho, S.-H.; Moon, S.-H. Fouling of an anion exchange membrane in the electrodialysis desalination process in the presence of organic foulants. Desalination 2009, 238, 60-69. [CrossRef]

24. $\mathrm{Wu}, \mathrm{J} . ;$ Contreras, A.E.; Li, Q. Studying the impact of $\mathrm{RO}$ membrane surface functional groups on alginate fouling in seawater desalination. J. Membr. Sci. 2014, 458, 120-127. [CrossRef]

25. Ahn, W.-Y.; Kalinichev, A.; Clark, M.M. Effects of background cations on the fouling of polyethersulfone membranes by natural organic matter: Experimental and molecular modeling study. J. Membr. Sci. 2008, 309, 128-140. [CrossRef]

26. Jin, X.; Huang, X.; Hoek, E.M. Role of Specific Ion Interactions in Seawater RO Membrane Fouling by Alginic Acid. Environ. Sci. Technol. 2009, 43, 3580-3587. [CrossRef]

27. Shan, L.; Fan, H.; Guo, H.; Ji, S.; Zhang, G. Natural organic matter fouling behaviors on superwetting nanofiltration membranes Water Res. 2016, 93, 121-132. [CrossRef]

28. Chen, L.; Tian, Y.; Cao, C.-Q.; Zhang, J.; Li, Z.-N. Interaction energy evaluation of soluble microbial products (SMP) on different membrane surfaces: Role of the reconstructed membrane topology. Water Res. 2012, 46, 2693-2704. [CrossRef] [PubMed]

29. Wu, H.; Shen, F.; Wang, J.; Wan, Y. Membrane fouling in vacuum membrane distillation for ionic liquid recycling: Interaction energy analysis with the XDLVO approach. J. Membr. Sci. 2018, 550, 436-447. [CrossRef] 
30. Lin, T.; Lu, Z.; Chen, W. Interaction mechanisms and predictions on membrane fouling in an ultrafiltration system, using the XDLVO approach. J. Membr. Sci. 2014, 461, 49-58. [CrossRef]

31. Lin, T.; Shen, B.; Chen, W.; Zhang, X. Interaction mechanisms associated with organic colloid fouling of ultrafiltration membrane in a drinking water treatment system. Desalination 2014, 332, 100-108. [CrossRef]

32. Kim, S.; Hoek, E.M. Interactions controlling biopolymer fouling of reverse osmosis membranes. Desalination 2007, 202, 333-342 [CrossRef]

33. Zhao, F.; Xu, K.; Ren, H.; Geng, J.; Ding, L. Impact of organic matter and calcium on nanofiltration membrane biofouling: XDLVO approach. China Environ. Sci. 2015, 35, 3602-3611.

34. Ding, Y.; Tian, Y.; Li, Z.; Wang, H.; Chen, L. Interaction energy evaluation of the role of solution chemistry and organic foulant composition on polysaccharide fouling of microfiltration membrane bioreactors. Chem. Eng. Sci. 2013, 104, 1028-1035. [CrossRef]

35. Yuan, W.; Zydney, A.L. Humic acid fouling during ultrafiltration. Environ. Sci. Technol. 2000, 34, 5043-5050. [CrossRef]

36. Bower, M.J.; Bank, T.L.; Giese, R.F.; van Oss, C.J. Nanoscale forces of interaction between glass in aqueous and non-aqueous media: A theoretical and empirical study. Colloids Surfaces A Physicochem. Eng. Asp. 2010, 362, 90-96. [CrossRef]

37. Feng, L.; Li, X.; Du, G.; Chen, J. Adsorption and fouling characterization of Klebsiella oxytoca to microfiltration membranes. Process Biochem. 2009, 44, 1289-1292. [CrossRef]

38. Qu, F.; Liang, H.; Wang, Z.; Wang, H.; Yu, H.; Li, G. Ultrafiltration membrane fouling by extracellular organic matters (EOM) of Microcystis aeruginosa instationary phase: Influences of interfacial characteristics of foulants and fouling mechanisms. Water Res. 2012, 46, 1490-1500. [CrossRef]

39. Zhao, F.; Xu, K.; Ren, H.; Ding, L.; Geng, J.; Zhang, Y. Combined effects of organic matter and calcium on biofouling of nanofiltration membranes. J. Membr. Sci. 2015, 486, 177-188. [CrossRef]

40. Listiarini, K.; Chun, W.; Sun, D.D.; Leckie, J.O. Fouling mechanism and resistance analyses of systems containing sodium alginate, calcium, alum and their combination in dead-end fouling of nanofiltration membranes. J. Membr. Sci. 2009, 344, $244-251$. [CrossRef]

41. De Kerchove, A.J.; Elimelech, M. Formation of polysaccharide gel layers in the presence of $\mathrm{Ca}^{2+}$ and $\mathrm{K}^{+}$ions: Measurements and mechanisms. Biomacromolecules 2007, 8, 113-121. [CrossRef]

42. Lindstrand, V.; Jönsson, A.-S.; Sundström, G. Organic fouling of electrodialysis membranes with and without applied voltage. Desalination 2000, 130, 73-84. [CrossRef]

43. Davis, T.A.; Volesky, B.; Mucci, A. A review of the biochemistry of heavy metal biosorption by brown algae. Water Res. 2003, 37, 4311-4330. [CrossRef]

44. Gao, F.; Wang, J.; Zhang, H.; Hang, M.A.; Cui, Z.; Yang, G. Interaction energy and competitive adsorption evaluation of different NOM fractions on aged membrane surfaces. J. Membr. Sci. 2017, 542, 195-207. [CrossRef]

45. Lin, T.; Lu, Z.; Chen, W. Interaction mechanisms of humic acid combined with calcium ions on membrane fouling at different conditions in an ultrafiltration system. Desalination 2015, 357, 26-35. [CrossRef]

46. Lee, S.; Elimelech, M. Relating organic fouling of reverse osmosis membranes to intermolecular adhesion forces. Environ. Sci. Technol. 2006, 40, 980-987. [CrossRef] [PubMed]

47. Ayala-Bribiesca, E.; Araya-Farias, M.; Pourcelly, G.; Bazinet, L. Effect of concentrate solution pH and mineral composition of a whey protein diluate solution on membrane fouling formation during conventional electrodialysis. J. Membr. Sci. 2006, 280, 790-801. [CrossRef]

48. Li, Q.; Elimelech, M. Organic fouling and chemical cleaning of nanofiltration membranes: Measurements and mechanisms. Environ. Sci. Technol. 2004, 38, 4683-4693. [CrossRef]

49. Fajardo-Diaz, J.L.; Morelos-Gomez, A.; Cruz-Silva, R.; Matsumoto, A.; Ueno, Y.; Takeuchi, N.; Kitamura, K.; Miyakawa, H.; Tejima, S.; Takeuchi, K.; et al. Antifouling performance of spiral wound type module made of carbon nanotubes/polyamide composite RO membrane for seawater desalination. Desalination 2022, 523, 115445. [CrossRef]

50. Lee, S.; Ang, W.S.; Elimelech, M. Fouling of reverse osmosis membranes by hydrophilic organic matter: Implications for water reuse. Desalination 2006, 187, 313-321. [CrossRef]

51. Chong, T.H.; Wong, F.; Fane, A. Enhanced concentration polarization by unstirred fouling layers in reverse osmosis: Detection by sodium chloride tracer response technique. J. Membr. Sci. 2007, 287, 198-210. [CrossRef]

52. Gao, X.; Guo, M.; Li, B.; Guo, J.Z.; Li, M.H. Interactions of bivalent metal ions and bovine serum albumins. J. Zhejiang A F Univ. 2013, 30, 777-783.

53. Ang, W.; Elimelech, M. Protein (BSA) fouling of reverse osmosis membranes: Implications for wastewater reclamation. J. Membr. Sci. 2007, 296, 83-92. [CrossRef] 